\title{
PREGNANT MOTHERS’ UNDERSTANDING ON MATERNITY BRAS
}

\section{NIROMI SERAM \& NIPUNI NARASINGHE}

Department of Textile \& Clothing Technology, University of Moratuwa, Katubeddha, Moratuwa, Sri Lanka

A properly designed, well-fitting maternity bra would be an excellent solution that could provide much relief to the wearer for the changes in the breast over the nine month period of pregnancy. Thus, this research is focused on investigating the pregnant mothers' understanding and preferences regarding maternity bras.

The individual views were gathered through a well-structured questionnaire that was distributed among pregnant mothers living in the urban and suburban areas of Kandy and Colombo in Sri Lanka. A descriptive analysis technique was adopted to analyze the collected data. Separate interviews were carried out with five pregnant mothers to clarify their responses to the questionnaire.

Results highlight that most of the mothers are looking for new bra types that could provide both greater comfort and adjust to the size change to overcome the inconvenience they have faced with regular bras that could not cope with the breast changes. Unfortunately, most of them were not fully aware of maternity bras and their features due to the unrestricted availability in the local market. Of those mothers who had a limited awareness of these matters, their priority preference has been on the choice of fabrics when purchasing a bra. Preference for using underwired bras dropped while preference for bras without hooks \& eyes increased during the last stage of pregnancy.

KEYWORDS: Breast Changes, Pregnant Mothers, Maternity Bras \& Bra Features
\end{abstract}

Received: Feb 25, 2019; Accepted: Mar 15, 2019; Published: Apr 06, 2019; Paper Id.: IJBMRJUN20191

\section{INTRODUCTION}

Since early times a variety of garments and accoutrements have been used by women to cover, reveal, restrain or to enhance the appearance of their breasts. The bra was originally invented with the primary purpose of increasing the wearers' comfort by supporting the breasts (Bloomers, 2012). The first modern bra that was patented in 1914 was a highly technical garment with different cup sizes that fulfilled the early requirement of women by supporting and shaping those appendages (Shin, 2009). Presently, after going through several stages of evolution, a variety of bra types based on body types, cut/ style, constructions and purposes are being marketed, namely full overs, convertible, pushups, maternity, demi, racer back, front closure, sports, full figure and padded.

\subsection{Breast Changes and Maternity Bras}

Changes happen to the breast during pregnancy to prepare them for feeding the baby. These changes are caused by an increase in the hormones Oestrogen, Progesterone and Prolactin, the last of which triggers the production of milk (Breast Cancer Care, 2014). Breast changes are usually one of the early signs of pregnancy, which may include tenderness of the nipples and breasts along with an increase in the size (Breast Cancer Care, 2014). These signs vary from woman to woman. It may be possible to notice a big change in the size or very little change at all (Breast Cancer Care, 2014). The breasts can feel heavy, and cause discomfort and pain because of 
these changes that occur during pregnancy (Bloomers, 2012). In such cases, a properly fitting maternity bra will prove an excellent solution and provide much relief to the wearer as Tripathi (2010) acknowledged "....health experts recommend supportive maternity bras, which are logically and practically designed to minimize common size discomforts and at the same time to bolster spirits and confidence". Therefore, switching from the normal bra to a maternity bra is a highly recommended move at the stage at which breast changes occur as indicated in table 1; however, that can be different from mother to mother.

Table 1: Breast Changes that Occur During Pregnancy (The Alpha Parent, 2012)

\begin{tabular}{|c|c|c|c|}
\hline Time Scale & Changes & Reasons & Solutions \\
\hline $\begin{array}{l}\text { Week 03-10 } \\
\text { (Month 01-03) }\end{array}$ & $\begin{array}{l}\text { - } \text { Breast tenderness } \\
\text { - Tingling and pricking sensation } \\
\text { around the nipple } \\
\text { - Nipples and areola become darker } \\
\text { - Increase in size of breast } \\
\text { - Breast may feel sore and nodular } \\
\text { - Small bumps appear around the } \\
\text { areola and they secrete an oil }\end{array}$ & $\begin{array}{l}\text { This is due to an } \\
\text { increase in the blood } \\
\text { supply and temperature } \\
\text { changes } \\
\text { To keep the skin supple } \\
\text { and prevent the growth } \\
\text { of bacteria }\end{array}$ & $\begin{array}{l}\text { Avoid wearing lace and } \\
\text { bras with seams across the } \\
\text { nipples as these can cause } \\
\text { irritation }\end{array}$ \\
\hline $\begin{array}{l}\text { Week 10-20 } \\
\text { (Month 03-05) }\end{array}$ & $\begin{array}{l}\text { - Colostrum may be exuded } \\
\text { - Drops of blood may also be seen } \\
\text { because sticky colostrum glues the } \\
\text { nipple to the inside of the bra and } \\
\text { tiny bits of skin are removed with } \\
\text { the bra } \\
\text { - Breast tenderness may diminish } \\
\text { during the latter stages }\end{array}$ & & $\begin{array}{l}\text { Switch over to a maternity } \\
\text { bra }\end{array}$ \\
\hline $\begin{array}{l}\text { Week 20-32 } \\
\text { (Month 05-09) }\end{array}$ & $\begin{array}{l}\text { - Dramatic increase in breast size } \\
\text { - Sweat rashes can occur } \\
\text { - Areola and nipple may be itchy and } \\
\text { dry }\end{array}$ & Due to sweating & $\begin{array}{l}\text { Change over to a larger } \\
\text { size, non-wired bra } \\
\text { Wear a bra that is not too } \\
\text { tight and is made of cotton } \\
\text { or some other breathable } \\
\text { fabric }\end{array}$ \\
\hline
\end{tabular}

Checking for adequate support, adjustability, coverage, fit and comfort is crucial when selecting a proper maternity bra. It is important to avoid bras with seams across the nipples as these may cause tickling and pricking sensations. It is good to stay clear of under-wires as these may restrict the blood supply and crush the developing milk ducts (The Alpha Parent, 2012). As the skin tends to become dry and itchy due to the rapid growth of the breast, the fabrics should be soft and permeable (i.e. breathable). Thus, bras that are designed for regular use may not be the most suitable ones to wear during maternity and the expected common features of the maternity bras can be presented as in table 2 .

Table 2: Common Features of Maternity Bras and their Purpose(Lutheran Children's Hospital, 2016)

\begin{tabular}{|l|l|}
\hline \multicolumn{1}{|c|}{ Features } & \multicolumn{1}{c|}{ Purpose } \\
\cline { 1 - 2 } Wide, Non-stretch, Cushioned shoulder straps & $\begin{array}{l}\text { Large, soft support area to prevent straps } \\
\text { from digging into shoulders }\end{array}$ \\
\cline { 1 - 2 } Wide bands & $\begin{array}{l}\text { To reduce surface pressure } \\
\text { For increased support and comfort }\end{array}$ \\
\cline { 1 - 2 } More coverage(cups, wings) & $\begin{array}{l}\text { To avoid scratching or irritating the skin; } \\
\text { especially around the nipples }\end{array}$ \\
\cline { 1 - 2 } Seamless cups & For wider size adjustment \\
\hline Limited decorative details (lace) & $\begin{array}{l}\text { For more comfort and to avoid sweat } \\
\text { rashes }\end{array}$ \\
\cline { 1 - 2 } $\begin{array}{l}\text { Soft, moisture absorbent, breathable fabrics and } \\
\text { cups }\end{array}$ & To adjust to the enlarged breasts \\
\cline { 1 - 2 } Stretchable cups and surrounds &
\end{tabular}


Therefore, it is clear that the maternity bra contributes to the comfort of pregnant mothers by readily accommodating the changes in the breasts in an effective manner. Even though the maternity outer wear provides much convenience, it is important to make sure that the undergarments are in order too as they too have a bearing on comfort. Therefore, this research attempts to investigate the pregnant mothers' understanding on maternity bras.

\section{METHODOLOGY}

An exhaustive literature survey was carried out to learn more about breast changes and other related body adaptations that occur during pregnancy. Relevant data were collected by using secondary sources, especially the Internet and other related health journals. Sufficient information was gathered at the beginning to gain a good knowledge of the breast and the changes it undergoes during the maternity period. After acquiring a clear picture of the research area, additional information was gathered by obtaining individual feedback from pregnant women.

Based on the simple probability sampling techniques, seventy-two (72) pregnant mothers from urban areas at different stages of pregnancy were selected randomly; a questionnaire was distributed among them focusing on key areas such as stage of pregnancy, breast changes experienced, currently used bra types, difficulties encountered and other pertinent matters.

Much of the primary data gathered through the questionnaire yielded considerable information, yet crucial information regarding certain key matters was not sufficient. Therefore, additional individual interviews were conducted with three pregnant mothers from the sample to obtain clarification on important areas. A clear response was sought to discover whether they were looking for specific features in a maternity bra such as absence of wires, better support, adjustability etc. It was also investigated whether the current bra types that were being used by the sample respondents incorporated the specific features desired in a maternity bra.

\section{DATA ANALYSIS AND DISCUSSIONS}

A detailed questionnaire was shared among 3 pregnant mothers as a pilot survey and the moderated questionnaire was distributed among 72 for the final survey. Then the entire list of responses was recorded and updated in an Excel worksheet. Most relevant parameters and the respective figures were analyzed accordingly. Results were filtered and recorded for the responses obtained from the 72 questionnaires.

\subsection{Overview of the Respondents}

According to the data gathered from the sample, majority (52\%) was between 26 and 30 years of age, with most of them experiencing pregnancy for the first time. Most of the women who already had children were older than 30 years and they constituted about $29 \%$ of the sample. About $12 \%$ were young women who were experiencing pregnancy for the first time. Majority (55\%) had no children and about $34 \%$ had a single child. The rest were going through their third maternity period as they already had two children.

\subsection{Breast Changes during Pregnancy}

When analyzing the progressive stages of pregnancy, it was noted that each stage returned a rather similar number of responses, which could lead to accurate results to a certain extent since the different samples were selected according to their stage of pregnancy. As most of the data collected in the research were tagged to the stage of pregnancy, the above equal distribution makes them more compatible and accurate. Majority (51\%) of the mothers noticed the breast changes 
between the $16^{\text {th }}$ and $20^{\text {th }}$ week of their pregnancy as shown in figure 1.

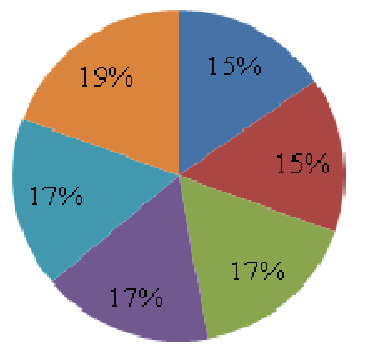

$$
\begin{aligned}
& \text { - 0-5 weeks } \\
& \text { - 6-10 weeks } \\
& \text {-11-15 weeks } \\
& \text { - 16-20 weeks } \\
& \text { - } 21-25 \text { weeks } \\
& =26-32 \text { weeks }
\end{aligned}
$$

Figure 1: Stages of Pregnancy

Most significant changes that occurred during the maternal period were breast tenderness and increase in breast size and more than $80 \%$ of the sample changed over to a new bra type with the pregnancy as presented in figure 2. It became apparent that most of the mothers were looking for new bra types that could offer comfort while accommodating size change to overcome the inconvenience they faced with the breast changes. The interview results also supports this 'it is difficult to wear the bra. I got sweat rashes. It is itchy. I had to change my bra” (contact- 1).

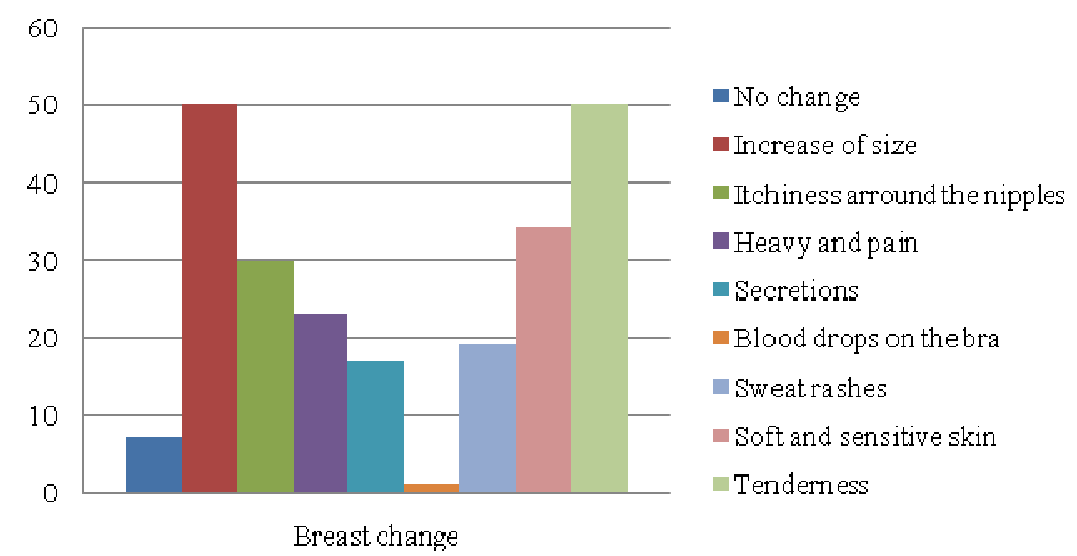

Figure 2: Significant Breast Changes

\subsection{Maternity Bras for Breast Changes}

When the mothers bought new bras during pregnancy, most of them changed the size but not the type. In fact, it was noticed that only $35 \%$ of the pregnant mothers were aware of Maternity bras as indicated in figure 3.
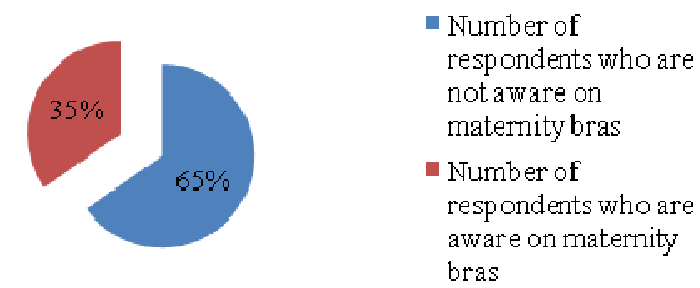

Figure 3: Awareness on Maternity Bras

Out of the knowledgeable mothers, the number who actually used the product was only $56 \%$ as shown in figure 4 . That was mainly due to the unavailability of maternity bras in the local market, which forced them to use the regular ones instead: "I have bought the larger size bras. But I couldn't get a maternity bra. Is it available here" (contact- 3). 

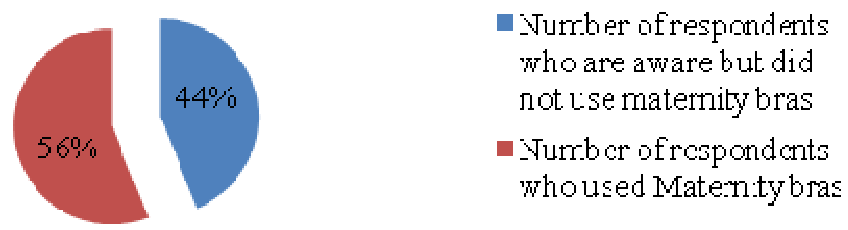

Figure 4: Usage of Maternity Bras

\subsection{Preferred Features of the Maternity Bras}

It was understood that on the question of preferences mothers had given their priority to the type of fabric when purchasing a bra. Cotton and other soft moisture absorbing fabrics were what they looked for when purchasing a bra. The absence of under-wires was their 3rd priority. Then rest of the sample preferred padded cups and absence of hooks $\&$ eyes mostly, whereas less priority was given to the adjustability feature. Therefore, it was understood that most of the mothers preferred bras without hooks and eyes.

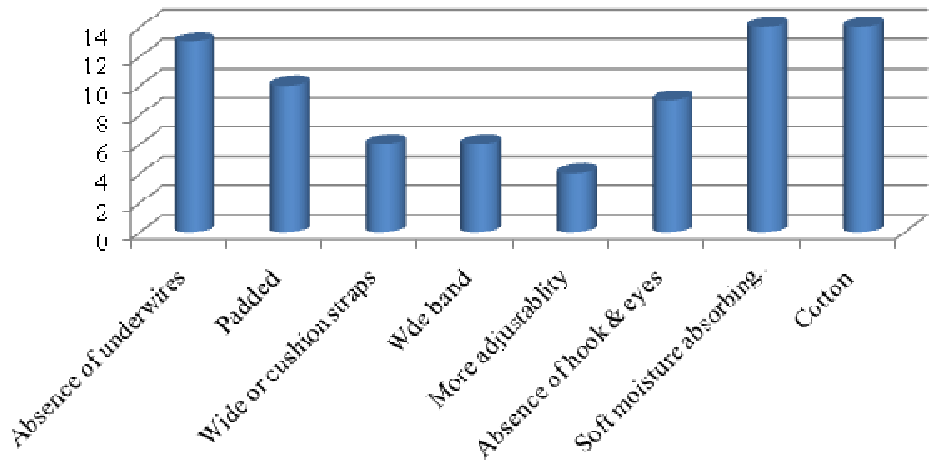

Figure 5: Preferred Features of Maternity Bras

After analyzing these preferences it became clear that the demand for the soft and moisture absorbing fabrics or cotton tended to increase with the increase of itchiness around the nipples and the sensitivity of the skin, which varied according to the stage of pregnancy as indicated in figure 6.

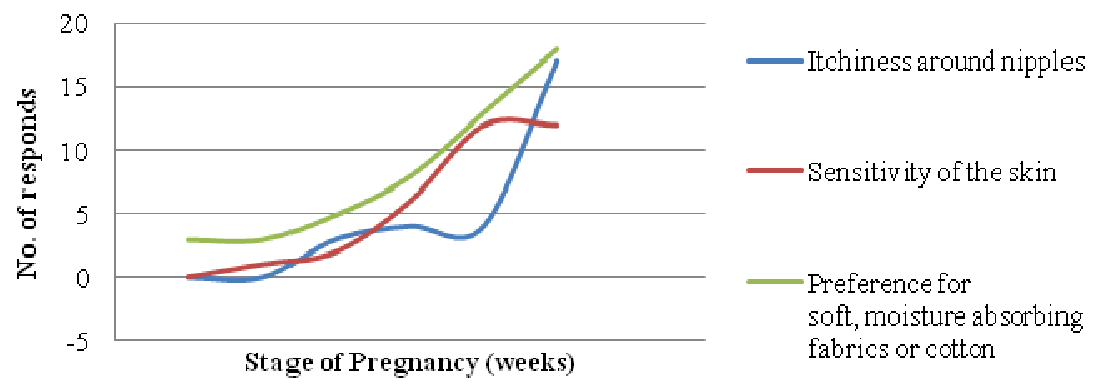

Figure 6: Preference for Soft Moisture Absorbing Fabrics or Cotton vs. Itchiness around the Nipples, Sensitivity of Skin

It can be seen that the usage of under-wired bras dropped as they increased the breast tenderness with the maturity of pregnancy; this indicates that mothers prefer to stay away from under-wires as they restrict the blood supply and crush the developing milk ducts. 


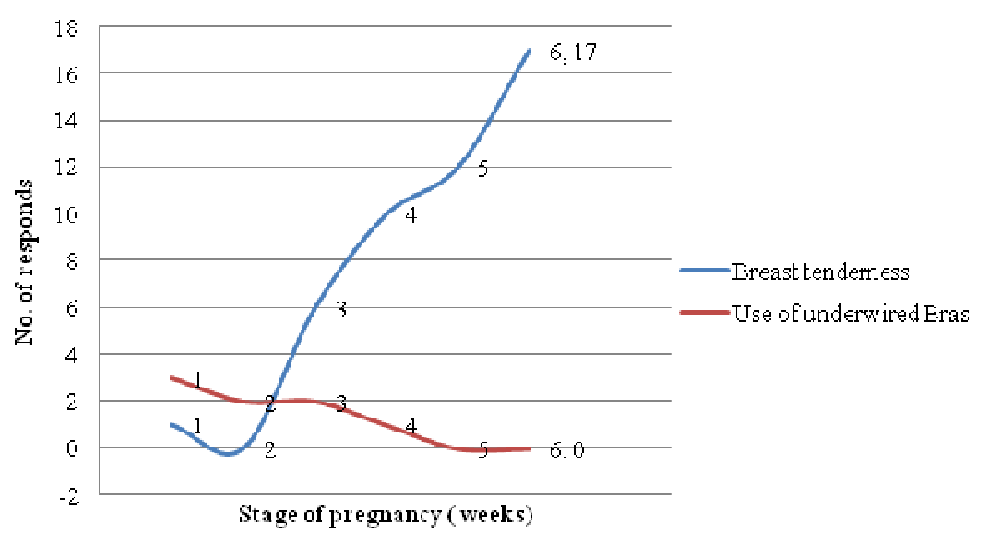

Figure 7: Breast Tenderness vs. Use of Under-Wired Bras

Preference for adjustability dropped and use of bras without hooks \& eyes (pullovers) increased as the stage of pregnancy progressed. This indicates that most of the mothers preferred the comfort more than the adjustability during the last stage of pregnancy.

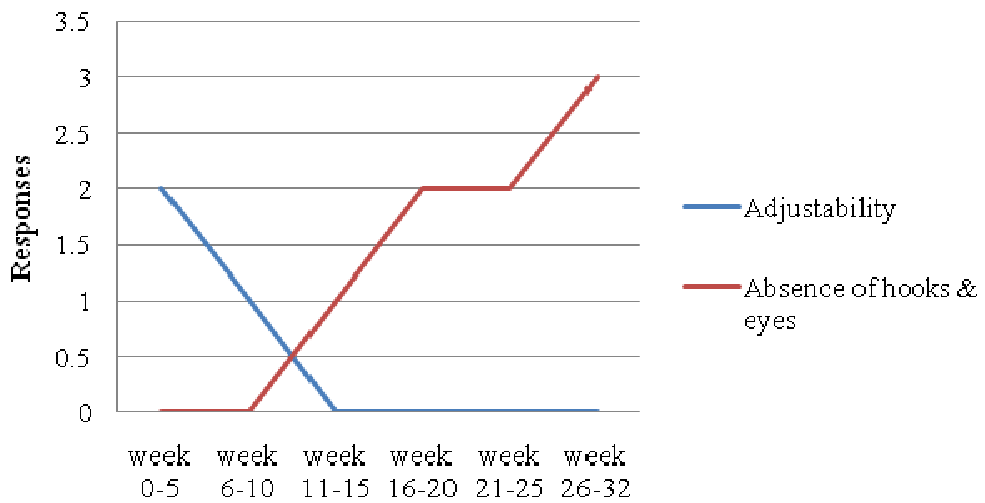

Figure 8: Preference for the Absence of Hooks \& Eyes and Adjustability as the Stage of Pregnancy Progressed

\section{CONCLUSIONS}

This research which focused on investigating pregnant mothers' understanding on maternity bras was mainly based on the urban pregnant mothers in Kandy and Colombo districts in Sri Lanka.

It was found that many of the pregnant women experienced breast changes at the initial stage of their pregnancy. The main changes that occurred in the breasts were tenderness and enlargement, with increased softness and sensitivity of the skin.

It was revealed that most of the mothers were looking for new bra types that would be more comfortable to wear and adjust to the size change so as to eliminate the inconvenience caused by the changes. However, it can be concluded that most of the pregnant women were not aware of maternity bras and their special features due to the lack of availability of these items in the local market. Of those mothers who were aware of it, the number that actually used the product was only $56 \%$.

It was also learnt that most of the mothers had given their priority consideration to the fabric when purchasing a bra due to the increasing itchiness they felt around the nipples and the heightened sensitivity of skin with the progression of pregnancy. It was also clear that the preference for using under-wired bras had dropped as the women wished to stay away 
from them as they had a tendency to restrict the blood supply and crush the developing milk ducts. Preference for adjustability had also dropped while the use of bras without hooks \& eyes (pullovers) increased mainly because the pregnant women attached more importance to the comfort of the bra than its adjustability during the last stage of pregnancy.

Further, it should be noted that this research findings can be useful for the intimate apparel companies to exploit the potential of manufacturing maternity bras and come up with suitable features that can cater to the needs of the pregnant mothers in Sri Lankan.

In concluding as above, it can be noted that, further studies would be advisable to obtain more accurate results. Accordingly, this study can be extended for other districts as well as the Asian region since this research has restricted to the urban pregnant mothers in Kandy and Colombo districts in Sri Lanka.

\section{REFERENCES}

1. Bloomers (2012). Bra Guide. Retrieved from:http://shopbloomers.com/wp-content/uploads/2012/09/bra-guide-WEB.pdf

2. Breast cancer care (2014). Breast changes during and after pregnancy. Retrieved from: https://www.breastcancercare.org.uk/sites/default/files/publications/pdf/bcc148_breast_chances_during_and_after_pregnancy _web.pdf

3. Lutheran Children's Hospital (2016). Maternity and Nursing Bras. Retrieved from http://www.lutheranchildrenshosp.com/pdfs/Breastfeeding_Bras.pdf

4. Shin, W. K. (2009). The origins and evolution of the bra. Doctoral dissertation. Retrieved from: http://nrl.northumbria.ac.uk/3040/1/shin.woo_phd.pdf

5. The Alpha Parent. (2018). The politics of Parenting: Timeline of Breast Changes in Pregnancy Retrieved from: http://www.thealphaparent.com/2012/08/timeline-of-breast-changes-in-pregnancy.htm

6. Sarkar \& Rasel, M.(2017) Maternity Clothing-A Comprehensive Review. Retrieved from: http://textilefocus.com/maternityclothing-comprehensive-review/

7. Shin, K. (2014) Maternity intimate apparel in the context of Hong Kong. Retrieved from: https://ia-technical.com/?p=1151 
